\title{
A Challenge for All: Successfully Transferring Wealth and Management on Family Ranches
}

\section{By Barry H. Dunn, Guest Editor}

There is no topic more important to rural America than this one. Major issues such as maintaining open space as wildlife habitat and view sheds, enhancing functional watersheds, food and fiber production from rangeland resources, and preserving our ranching and bunting heritage are at stake. We must make sure this generational transition happens on a landscape scale, or we lose something precious and dear to all of us.

-Dr Fred Bryant, Director, Caesar Kleberg Wildlife Research Institute, Texas A\&M

University-Kingsville and Past President of the Society for Range Management

$\widetilde{\Gamma}$ have the honor to know, and to count as friends, a family in South Texas whose grandchildren represent the ninth generation on the same ranch. The A. T. Canales Ranches of Premont, Texas, started as a Spanish land grant in the 1770s. Today this ranch, whose history would fill volumes of "can't put it down" reading, is successfully operating with cattle, horses, wildlife, and minerals. As I interact with them, I can't help but wonder if the ranch's main purpose in 2009 is to provide a glue to hold a diverse modern family together.

Questions abound! How on earth was a single family able to ranch for nine generations? On the very same ranch, this family has been governed by three different nations. From the very same ranch this family has helped build and maintain communities of several ethnicities. For hundreds of years they have made decisions about resource management. For hundreds of years they have made stocking rate decisions. For hundreds of years they have harvested wildlife for food, and more recently for sport. For hundreds of years they have bought and sold cattle and horses. How many times have they successfully transferred not only the wealth represented by a ranch, but also the keys to successfully managing some of the toughest country I have seen? And all the while, they have held their family together! How did grandfathers and grandmothers teach their grandchildren and great-grandchildren? What could we learn about communication and relationships if we were privileged to hear their family stories? What could we learn about rangeland, ranching, and community if we had the honor to read and understand their family history?

As I ponder these questions, it seems there are two distinct aspects of rangeland management that, while of critical importance, seem to elude our understanding. The first is the temporal aspect. As rangeland professionals, scientists, managers, and ranchers, we search to understand the impact of our decisions on the many diverse perspectives of range management. Yet, constrained by expectations for quick results, economics, and the span of our careers, a deep understanding of the long-term impacts of our decisions all too often evades us.

The second aspect is transition. As we gaze with wonder at the vistas of Western rangelands, I am concerned that the magnitude of the resource lulls us into a false sense of permanence. The fact is that whether the rangeland resources we discuss are privately or publically owned, management of those resources is constantly in transition. Driven by policy, economics, longevity, fact, and fads, management of the rangelands of the West has changed in so many ways and so many times that its resilience to weather and climate seems minor by comparison. Understanding the impact of the management choices we have made is difficult. Understanding the impact one management decision in concert with others, over time, is something else again. It, too, eludes us.

Whether we understand them or not, these two aspects, time and transition, collide with range management at a critical moment: when the management and ownership of a ranch passes, or does not pass, from one generation to 
the next. Although the transfer of a ranch business to succeeding generations is an issue that often weighs heavily on the minds of ranch families, it is a topic that is of critical importance to all who are interested in reliable stewardship of rangeland resources. To ensure a viable future for the next generation, succession planning should be a priority for every family ranch business, and all interested organizations and institutions should lend a hand. All too often, for a family ranch, the consequence of inaction is loss of financial resources and termination of the family legacy. The price tag for society is the fragmentation of fragile resources, demise of communities, and loss of the wisdom that guided historical and appropriate management of these same precious resources.

The topic of the 2008 HOLT CAT Symposium on Excellence in Ranch Management hosted by the King Ranch Institute for Ranch Management was "Living the Legacy: Transitioning Ranch Ownership and Management to the Next Generation." I hope you read, enjoy, and learn from the following four papers presented at the symposium. Leading national experts graciously allowed four graduate students in the King Ranch Institute for Ranch Management to join them as coauthors. Although the topic of transitioning wealth and management may seem unusual for Rangelands and the Society for Range Management, it has been the most frequently requested symposium topic received from ranchers over the last 5 years. In discussions with Extension Range Specialists from other regions and states, this mirrors requests for information in their areas. Clearly, this is a topic of interest and importance. The article by Danny Klinefelter and Brent McCann, "Management Transitions: Handing Over the Reins," has applications to organizations and agencies of all types.

Passing a lifetime's worth of work to the next generation is a task that requires decision-making, communication, and dedication. Once in place, a comprehensive and dynamic estate and management plan can provide peace of mind for the entire ranch family. In the end, the reward for a ranch family is the preservation of its wealth and its legacy. The rewards for society are incalculable.

Author is Associate Professor, Texas AEM University-Kingsville, and Executive Director of the King Ranch Institute for Ranch Management, Kingsville, TX 78363, USA, kabbd00@tamuk. edu.

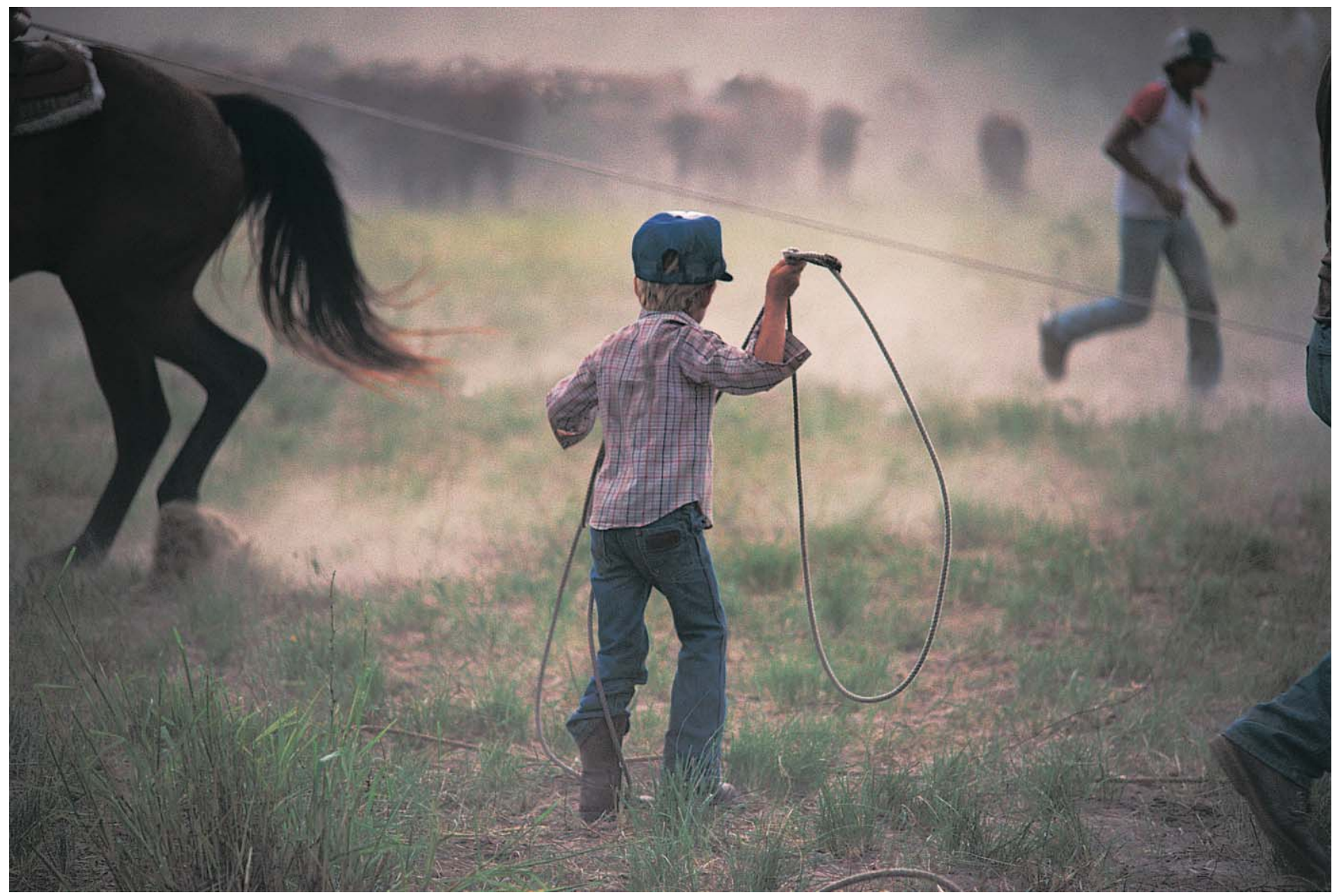

Small boy, big loop. Photo by Janell Kleberg. 